\title{
СОЗДАНИЕ СЕТЕЙ 5G - вопрос политический
}

Рассказывает заместитель руководителя ЦК НТИ БСИВ при Сколтехе В.Э.Шуб

DOI: $10.22184 / 2070-8963.2019 .81 .4 .8 .11$

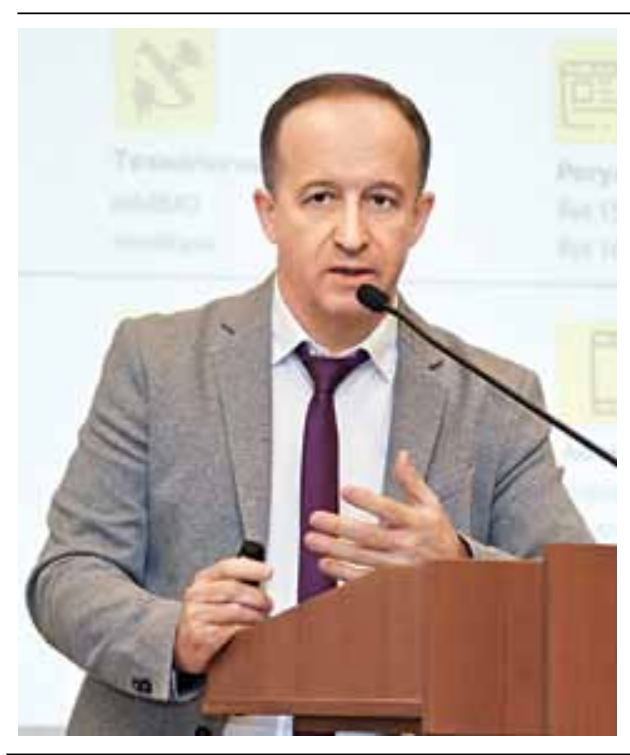

Всем очевидно, что через некоторое время сети 5G станут нормой как для всего мира, так и для России. Однако в нашей стране нет производителей оборудования для этих сетей, а в условиях санкционной действительности зависимость от зарубежных поставщиков становится серьезной угрозой национальной безопасности. Это понимают в "верхах" - и разработка комплексного отечественного решения $5 \mathrm{G}$ сейчас в процессе закрепления в программе "Цифровая экономика". Однако путь от решения до его реализации весьма тяжел, начиная с "частотных терниев".

Решение вопросов технологической независимости, скорейшей локализации или создания с нуля полностью отечественного решения 5G стало приоритетной задачей Центра компетенций Национальной технологической инициативы по беспроводной связи и Интернету вещей (ЦК НТИ БСИВ) (далее-Центр) при Сколтехе. О позиции Центра в отношении создания в России сетей $5 \mathrm{G}$, о его роли и задачах ПЕРВОЙ МИЛЕ рассказал заместитель руководителя ЦК НТИ БСИВ В.Э.Шуб.

Виталий Элконович, что представляет собой Центр компетенций Национальной технологической инициативы по беспроводной связи и Интернету вещей (ЦК НТИ БСИВ) при Сколтехе, кто в нем работает?

Центр был создан для реализации работ в рамках программы PBК с целью разработки комплементарных для российского рынка стандартов и технологий, которые входили бы в общую экосистему Интернета вещей. Также предполагается, что он должен стать проводником идеи создания локального комплексного сетевого решения сотовой связи 5-го поколения для того, чтобы обеспечить технологическую независимость локального рынка от возможных санкционных рисков. Мы видим, что связанные с ними угрозы и опасности не только не рассасываются, но приобретают все больший масштаб, глобализуются. Мир меняется, и смысл деятельности Центра сводится к тому, чтобы сделать его на дан ${ }^{-}$ ном конкретном рынке более безопасным, защищенным и устойчиво развивающимся.

Мы собираем лучших разработчиков в области Интернета вещей, в области беспроводной связи. Это специалисты по сетевым решениям, по компонентной базе, по программному обеспечению, которые сейчас выполняют контрактные исследования в области систем связи 5-го поколения, с перспективой на 6-е поколение.

Каковы ваши функции и полномочия как заместителя руководителя Центра?
Я занимаюсь в основном вопросами, связанными с разработкой технологической и бизнес-стратегий Центра, и реализую собственные компетенции. По образованию инженер электронной техники, кандидат физико-математических наук, с 1994 года я работаю в телекоммуникационной отрасли, по времени примерно поровну на разных "сторонах баррикад" - в компанияхпроизводителях оборудования сетевой инфраструктуры и операторских телекоммуникационных компаниях. Ровно четверть века назад начал свою деятельность в AT\&T NSI в должности директора по стратегическим проектам, и эта компания стала для меня хорошей профессиональной школой. Потом была работа в отделении сотовой инфраструктуры 
компании Motorola ECD ICIC $\mathrm{CmbH}$, затем - в L.M. Ericsson AB, где занимался и мобильной, и фиксированной связью. А в 2003-2016 годах работал в трех национальных операторских компаниях - РТРС, ОАО "Система Масс-Медиа" ("СММ") АФК "Система, ЗАО "Компания "ТрансТелеКом". Там выполнял функции технического стратега и лидера в области создания технологической инфраструктуры, формирования единой технической политики, реализации сетевых решений. В 2016-м вернулся к производителям оборудования, но уже российским - до Сколтеха работал в IPG Photonics Russia, HTO "ИРЭ-Полюс" заместителем генерального директора по бизнеснаправлению "Телеком". Сейчас мне очень удобно и комфортно работать, потому что знаю изнутри обе стороны и легко могу поставить себя на место и производителя оборудования, и оператора. Мне известно, как в этих компаниях работают техническая и коммерческая системы, как формируется технологическая политика, политика бизнес-менеджмента, выбора партнеров и т.д. - это дает возможность грамотно выстраивать стратегию ЦК НТИ в направлении взаимодействия и с потенциальными технологическими партнерами, и с"большой пятеркой" операторов.

А также, вероятно, это помогло создать "Клуб 5G" при цК НТИ? Расскажите о нем, пожалуйста.

Да, это была наша инициатива. И первое же наше совместное собрание операторского "Клуба 5C" и технологического "Консорциума 5G", проведенное 31 мая, вызвало колоссальный интерес. Это был некий тест - и мы убедились, что реакция рынка исключительно позитивная. "Клуб 5С" - это инициатива в какой-то степени комплементарная, но ни в коем случае не конкурирующая с "Союзом LTE", на заседаниях которого обсуждаются в основном вопросы радиочастотного регулирования и выделения операторам частотного ресурса.

Мы в вопросах радиочастотного спектра занимаем выжидательную позицию: сначала регулятор выделит частоты, а потом под них уже будет производиться оборудование. Но, с другой стороны, поскольку сейчас неизвестно, какие частотные полосы будут выделены, кому и на каких условиях, смысл нашей стратегии состоит в том, чтобы хеджировать риски и быть подготовленными к любым сценариям. Поэтому идея "Клуба 5G" заключалась в том, чтобы собрать вместе всех основных фигурантов рынка и попытаться выработать некие общие технические решения, технические требования и задания на некую идеализированную систему 5-го поколения. В дальнейшем она могла бы быть так или иначе использована, поскольку в нее заранее должны быть заложены такие критичные ключевые критерии, как минимизация санкционных технологических и коммерческих рисков. В то же время операторы, которые выступали у нас на собрании "Клуба 5G", уже сейчас сформулировали три обязательных требования к будущим продуктам: конкурентная цена, техническая конкурентоспособность, минимизация массо-габаритных показателей и требований по энергопотреблению и тепловыделению.

Вы являетесь участником рабочей группы по созданию "дорожной карты" развития беспроводных технологий, предполагающей локализацию в России производства оборудования для радиосетей. Какова роль Центра в этой разработке?

Как члены рабочей группы, мы внесли определенный вклад и по общему концептуальному видению процесса, и по конкретным вопросам. При этом принципиально важно, что сейчас выкристаллизовалась ключевая, лидирующая роль Сколтеха. Причина проста: очень много фигурантов рынка в России являются объектами санкционных ограничений. Сколковский институт науки и технологий - это политически неангажированная и нейтральная по отношению абсолютно ко всем и производителям, и операторам структура, которая не находится ни под какими санкционными ограничениями. По сути, Сколтех является образовательным учреждением, автономной некоммерческой организацией.

Мы - нейтральный дизайнцентр. Наша программа предполагает прежде всего создание архитектуры и компонентной базы сетевого решения полноценных систем сотовой связи пятого поколения, которые будут минимально уязвимы к любым возможным санкционным ограничениям, - и мы можем взять на себя функцию интерфейса между поставщиками элементов и полных сетевых решений и теми, кто будет реализовывать общее решение, когда оно будет выработано.

Как организовать процесс локализации производства оборудования для радиосетей?

У нас есть три четких плана, которые воплощаются параллельно. План "A" нацелен на прямое сотрудничество с основными игроками рынка первого эшелона. В этом направлении мы ведем переговоры с некоторыми производителями единого решения на предмет локализации, ищем с ними точки соприкосновения, возможные варианты сотрудничества в интересах обеих сторон. В рамках плана "Б" мы ищем на рынке ключевые компоненты единого сетевого решения, которые 
предлагаются более мелкими независимыми поставщиками. С теми, кто готов их нам продать, ведем переговоры. И, наконец, по плану "C" мы готовим кальку общего технического решения с тем, чтобы потом непосредственно с производителями компонентной базы начать его реализовывать в "железе" как решение с нуля.

Какие сроки выполнения этих планов ставите?

Сроки плавающие, потому что неизвестно, когда будут выданы лет развития сформировался совершенно четкий операторский бизнес-кейс. Он сводится к простому правилу: чем ниже частота, тем меньше затраты на покрытие территории. Это физика распространения радиоволн - дан ность, которую никто не может опровергнуть, потому что природу обмануть невозможно. И не стоит даже пытаться. Все, кто пытается, - рано или поздно терпят поражения. Физика распространения радиоволн при покрытии территории вне помещения и вну-

\section{Мы - нейтральный дизайн-центр}

частоты. Для нас исключительно важно, чтобы регуляторы как можно быстрее определились с выделением частотного спектра, потому что это позволит нам расставить приоритеты в разработках. Понятно же, что базовая станция (точнее, ее приемопередатчики), работающая в диапазоне ниже 1ГГц, схемотехнически очень слабо похожа на БС, которая работает в миллиметровом диапазоне. Это два совершенно разных продукта, они требуют разной компонентной базы. В зависимости от того, какие частотные диапазоны будут использоваться, количество требуемых для сотовых систем 5-го поколения в России может варьироваться от 100 тыс. до 1 млн базовых станций. Нижние частоты требуют меньшего количества БС, верхние - большего.

\section{Какие диапазоны частот,} на ваш взгляд, оптимальны для 5G?

Свою позицию мы твердо определили и всячески стараемся донести свое видение регуляторам. В сотовой связи за десятки три него диктует сотовым операторам бизнес-стратегию: начинать разворачивать сеть нужно с низкой частоты, которая обеспечивает максимально экономичное покрытие вне зданий и внутри них. Дальше происходит создание хот-спотов с более высокими частотами - в бизнес-центрах, торговых центрах, на стадионах, в различных учреждениях. Обратная логика не работает. Все попытки заходить в сотовую связь сверху частотного диапазона проваливаются. Единственный удачный опыт был у компании Tele2, которая сразу покрыла Москву частотами 2,1 и 1,8 ГГц. Это потребовало, конечно, большого количества базовых станций, мощной опорной сети, но оператор с этой задачей справился, честь ему и хвала. Но следующий же частотный рубеж - 2,6 ГГц - привел компанию "Йота" к коммерческой неудаче, причем дважды, сначала в стандарте Mobile WiMAX, а потом - в LTE. Это показывает, что в сотовой связи есть совершенно четкие частотные рубежи, которые определяют весь бизнес-кейс операторов. Он предельно простой: ниже 1 ГГц базовое покрытие экономично; от 1 до 2,1 ГГц - покрытие "второго яруса" в местах более массового скопления абонентов; все, что выше - это уже хотспоты между 2,5 и 4 ГГц, где сота работает почти в условиях прямой видимости и на переотражениях от стен зданий. "Пробить" две стены на частоте 2,5-4 ГГц в обратном канале от абонента получается уже тяжело. В более высоких частотах ситуация нам не очень понятна. Так, Сколтеху для организации демо-зоны 5C и тестирования технологий выде лены частоты 4,8-5 ГГц - и мы сейчас ищем на рынке приемопередатчики в этом диапазоне. Искать очень тяжело, поскольку 4,8-5 ГГц - это так называемый "китайский" диапазон, а наш рынок в этом направлении еще не раскачался. Но в любом слу чае понятно, что покрытие в этом диапазоне весьма ограниченное.

Возвращаясь к низким частотам, хочу напомнить о "цифровом дивиденде". Мое частное экс пертное мнение состоит в том, что в этой области России необходимо использовать американ ский опыт, поскольку в обеих странах очень большие территории, неравномерная плотность населения и высокий уровень урбанизации. Поэтому нужно активно расчищать под сотовую связь частоты аналогового эфирного телевидения. В США компания T-Mobile исключительно успешно использовала купленный на аукционе большой частотный ресурс в диапазоне 600-700 МГц, полученный в результате высвобождения частот аналогового эфирного телевидения. Оператор совершил колоссальный рывок, резко усилил свои конкурентные позиции, получив огромную дополнительную долю рынка после запуска сети на этих частотах. Я считаю, что настал момент 
реализации такого подхода и в России.

Поэтому мы говорим телекоммуникационному сообществу: давайте приоретизируем эту ситуа цию. Сначала в низкочастотном диапазоне (ниже 1 ГГц), с исполь зованием "цифрового дивиденда", нужно дать операторам возможность обеспечить ковровое покрытие - именно покрытие! - территории сетями 5G. А дальше вполне можно начать "играть" с рефар мингом имеющихся у операторов, построивших сотовые сети 2-го, 3-го и 4-го поколений, частот в диапазоне 1,9-2,6 ГГц. Вопрос возможности для операторов рефарминга лежит в области технологической нейтральности. Дальше идет диапазон 3,4-3,8 ГГц. На этой площадке сейчас работает спутниковая связь и спецсвязь-и, конечно, представители этого сегмента отрасли совершенно правы, заявляя: нельзя просто взять и выключить их системы ради развертывания сотовых сетей нового поколения, потому что это вопрос национальной безопасности. Следующие диапазоны - 5-6 ГГц и миллиметровый. Для нас сейчас "миллиметры" являются не совсем понятной сущностью, потому что первые развернутые в этом диапазоне сети в США повлекли очень много проблем и вопросов со стороны абонентов, поскольку при очень высоких скоростях передачи в пределах видимости БС сигнал пропадает внутри помещений.

Почему так сложно решается вопрос с выделением частот?

Потому что частот нет. Они заняты, их надо расчищать. Поймите, что произошло. Российская сотовая связь наступила на те же грабли, на которые наступила российская железная дорога. В свое время, когда ее строили, было решено сделать колею на несколько дюймов шире, чем в Европе. И сегодня железнодорожные сети
России несовместимы с сетями Европы. Так и частотный план в Советском Союзе был сознательно сделан несовместимым с частотным планом Европы. В результате те частоты, которые в Европе изначально при необходимости развивались для гражданской радиосвязи, в СССР оказались занятыми военными и прочими спецсредствами. Я прекрасно помню, как в 1995-м году на согласительном совещании представитель министерства связи РФ заявил, что если "ВымпелКому" выдать вторую лицензию на GSM-900, то самолеты в аэропортах начнут падать, поскольку это их частоты - радиоприводов аэродромов. Тем не менее "ВымпелКом", потом "МегаФон" получили лицензии - и самолеты не падали, потому что проблема была решена. Но это был долгий путь, потребовавший много усилий и денег. Каждое поколение сотовой связи наступает на одни и те же грабли. Я участвовал в создании сотовых сетей всех поколений, и то, что сейчас происходит, - для меня дежавю. Все это было, и не один раз.

\section{Ваш опыт, интуиция - что подсказывают?}

Подсказывают они одно: такого рода вопросы в России решаются исключительно волевым путем. Поскольку окно возможностей постепенно сужается, а страна не может выпадать из глобального поля радиопокрытия, потому что это вопрос международного роуминга, вопрос соответствия национальной информационной инфраструктуры инфраструктуре соседей и на Западе, и на Востоке (а сейчас сопредельный Китай развит в плане сотовой связи не хуже, чем Европа, а в каком-то смысле даже лучше), - поэтому вопросы соответствия должны и будут решаться.

Насколько я понимаю, постепенно формируется некий консенсус людей, принимающих решения, потому что эта проблема должна решаться. Формируется, условно говоря, система прика зов, которая должна обеспечить решение этих вопросов. Это вне нашего поля деятельности, мы можем только давать свои рекомендации, высказывать публично свои соображения относительно приоритетов, которые должны быть расставлены. Наша позиция неизменна, ее мы пытаемся всем донести, она отражена и в "маршруте": начинать нужно с диапазонов ниже 1 ГГц. В принципе, против этой позиции никто формально не возражает, потому что почти все учились в каких-то вузах и знают, что радиоволна в диа пазоне 600-900 МГц бьет дальше и проникает глубже, чем волна в диапазоне 1,8 , или 2,1, или 3,8 ГГц.

Может быть, эта позиция должна быть закреплена правительственным документом?

Если вы могли заметить, сейчас вопросы своевременного покрытия территории страны сетями 5G приобрели практически национальный приоритет. Они регу лярно обсуждаются первыми лицами государства, регуляторами, главами ведущих частных и государственных компаний. То есть постепенно возникло понимание, что этим вопросом надо заниматься, ему нужно присваивать достаточно высокий приоритет. Есть надежда, что, учитывая опыт создания предыдущих поколений сетей, принимающие решения люди договорятся между собой и примут реалистичную программу действий, наце ленную на оптимальное и скорейшее решение этих вопросов.

\section{Спасибо} за интересный рассказ. С В.Э.Шубом беседовала Л.В.Павлова 